\title{
Rapid Assessment of Genetic Variation for Morphological Traits in Sweetbay Magnolia Using a Container Production System
}

\author{
Peter J. Zale ${ }^{1}$, Daniel K. Struve ${ }^{2,4}$, Pablo Jourdan ${ }^{3}$, and David M. Francis ${ }^{3}$ \\ Department of Horticulture and Crop Science, The Ohio State University, 2021 Coffey Road, \\ Columbus, OH 43210
}

\begin{abstract}
AdDitional INDEX wORDs. narrow sense heritability, selection index, ideotype, germplasm, branching habit, bud dormancy
ABstract. Breeding and development of ornamental woody plants for specific ideotypes will provide diverse choices to meet specific needs for natural and constructed landscapes. An $\mathbf{F}_{1}$ half-sib family analysis of Magnolia virginiana generated from controlled pollinations was implemented to identify potential juvenile selection strategies for two mature ideotypes: a compact and rounded shrub form (to $2.5 \mathrm{~m}$ tall and wide) and a single-stemmed, small tree form (to $4 \mathrm{~m}$ tall), both with abundant flowering. The 2-year test was conducted in a container nursery. Fourteen traits were measured in 2007 and 2008, including height at three intervals (July, August, and September), mean branch length and branch count, early and late flower production, collar sprout formation, stem diameter, and branch angle. There were significant differences between $F_{1}$ half-sib families $(P \leq 0.0001)$ for all traits. Phenotypic and genetic correlations and narrow sense heritability were estimated for these traits. Phenotypic and genetic correlations showed favorable associations among branch count, caliper, and early flower production. These traits were used to form a selection index for a shrub ideotype. Also, there were positive phenotypic and genetic correlations between height and late flower production, which were both negatively correlated with collar sprout formation. These traits were used to form a selection index for the single-stemmed, small tree ideotype. Narrow sense heritabilities were high for most traits in 2007 but were lower in 2008. Results suggest that selection of phenotypes ranking highest for the traits of interest may yield the desired ideotypes. However, introduction of additional genetic variation through new germplasm accessions may be necessary to maintain breeding progress.
\end{abstract}

Magnolia virginiana var. virginiana (sweetbay magnolia) is a native component of the flora of the eastern U.S. coastal plain and mid-Atlantic states and is used as an ornamental plant in commercial and residential landscapes. The species is noteworthy for its large, fragrant white flowers produced over a long period, starting in mid-May and lasting until mid-July (Blake and Struve, 2007). This magnolia is one of the most adaptable for the midwestern United States, growing well on a range of soil $\mathrm{pH}$ levels and soil types and surviving winters in U.S. Department of Agriculture (USDA) plant hardiness zone 5 (Callaway, 1994; Nash and Graves, 1993; Spongeberg, 1976; Treseder, 1978). Additional ornamental traits include a late summer display of red follicles, semievergreen to evergreen foliage, aromatic leaves and bark, and use as a plant attractive to wildlife (Priester, 1990).

Although various cultivars of $M$. virginiana var. virginiana have been described, none plays a dominant role in the nursery industry; these selections are the result of happenstance rather than systematic improvement programs. We have defined two desirable ideotypes for $M$. virginiana: first, a compact shrub form 2 to $2.5 \mathrm{~m}$ tall and 2 to $2.5 \mathrm{~m}$ wide with abundant flowering; and second, a single-stemmed small tree with a mature size of

Received for publication 3 Aug. 2010. Accepted for publication 12 Jan. 2011. Salaries and research support provided by state and federal batch funds appropriated to OSU/OARDC.

We thank Mr. Rich Pratt and Mr. Daniel Robarts for invaluable assistance necessary for the completion of the manuscript.

${ }^{1}$ Graduate Research Assistant.

${ }^{2}$ Professor.

${ }^{3}$ Associate Professor.

${ }^{4}$ Corresponding author. E-mail: struve.1@osu.edu.
3 to $4 \mathrm{~m}$ tall and 2 to $3 \mathrm{~m}$ wide and with abundant flowering. Ideally forms would be evergreen, hardy to USDA plant hardiness zone 5, adaptable to various soil types, easily propagated by sexual or asexual means, and amenable to container and field nursery production systems.

Extensive phenotypic variation occurs in $M$. virginiana, and there exists opportunity for selection toward our proposed ideotypes (McDaniel, 1966, 1970, 1984; Treseder, 1978). Cultivar selections have been made on various characteristics such as evergreen foliage, quality of foliage coloration, precocious flowering, shrub and tree form habit, rapid growth, and hardiness; but none of these individual selection criteria fully embodies the ideal cultivar described by our ideotypes (Callaway, 1994; Gardiner, 2000; McDaniel, 1984; Treseder, 1978). Magnolia virginiana is comprised of two botanical varieties: The more southern $M$. virginiana var. australis and the northern $M$. virginiana var. virginiana each have some of the desired characteristics, but neither has the full combination of traits. For example, the northern botanical variety tends toward a multistemmed, shrublike growth habit, whereas the tree form predominates in the southern botanical variety (Callaway, 1994). Magnolia virginiana is later flowering and tends to escape the late spring frosts that damage the flowers of the popular precocious flowering species of Magnolia (subgenus Yulania). We have noted that some individuals repeat bloom during the late summer, beginning mid-August, and can flower until the onset of frost in the Columbus, $\mathrm{OH}$, area.

The limited breeding work that has occurred with $M$. virginiana has focused on the creation of interspecific hybrids with the goal of improved flower quality, flower color, or flowering period. There have been no reports of studies on other 
morphological characteristics of $M$. virginiana such as height, branching pattern, or flower abundance that could be incorporated into schemes of general species improvement for varied landscape applications or for development strategies for novel characteristics. We developed a diverse population suitable for evaluation of morphological and flowering characteristics and to assess whether a container production system could be used to accelerate genetic testing (Struve and McKeand, 1993). The objective was to determine the degree of genetic control over these traits when plants were grown in a container nursery and examine genetic variation in the population to help guide decisions regarding plant selection and cultivar development.

\section{Materials and Methods}

A breeding population was derived from seed collected from 30 phenotypically superior source trees in Columbus, $\mathrm{OH}$, ranging in age from an estimated 10 to 50 years old. Because it is later flowering than precocious Asian magnolias, this tree is among the most commonly planted magnolia species in central Ohio. The origin of these trees was unknown and assumed to be from unrelated seedlings, potentially arising from various nursery sources. Despite this, it is likely that all plants in our trial represent the northern haplotype and may be phylogenetically more closely related than trees from other portions of the species range that exhibit different haplotypes (Azuma et al., 2011).

Seeds from these trees were collected and bulked; 1000 seedlings were subsequently raised from this seed and grown in containers for 2 years. From this population, 10 parent trees were selected and transplanted to a field plot at the Waterman Learning Laboratory on The Ohio State University (OSU) campus in Columbus. Selection criteria for the 10 parent trees were: cold hardiness in USDA plant hardiness zone $5(-23.4$ to $-28.8^{\circ} \mathrm{C}$ ), adaptability to container production as expressed by rapid growth (as determined by height and stem diameter measurements), and by their ability to be successfully transplanted and established with minimal aftercare.

The parent trees of the $F_{1}$ half-sib families varied in phenotypic expression for the traits measured in this study. Eight of the parent trees were named by their accession numbers: \#28, \#29, $\# 31$, \#33, \#34, \#35, and \#36. The two remaining parent trees, " $S$ " and "K," were named after their current locations: the "S" was identified as a superior seedling growing on D.K. Struve's property and tree " $\mathrm{K}$ " from the OSU campus on Kinnear Road.

Pollen was collected according to Jonsson (1987), and pollinations were performed during May 2006 using a partial diallel mating design (Blake and Struve, 2007). From May to Aug. 2006, 462 reciprocal crosses were performed. Of these 462 crosses, 115 resulted in successful formation of fruit. Successful pollination was defined as the formation of one or more follicles per follicetum. Detailed information about parent trees and pollination procedures was presented in Blake and Struve (2007).

Parent trees were given supplemental water and $21 \mathrm{~N}-2.9 \mathrm{P}$ 4.3K fertilizer (J.R. Peters, Allentown, PA) throughout the growing season to promote vigorous growth and ensure seed set (Blake and Struve, 2007). The planting area was kept free from weed competition with wood chip mulch and post-emergence herbicides.

Seeds were harvested from parent trees in September, cleaned, and placed in plastic bags with moist peatmoss in a $7.2{ }^{\circ} \mathrm{C}$ walk-in cooler for a 90 -d cold stratification period (Del Tredici, 1981; Dirr, 1998; MacDonald, 1986). Seeds were sown in late Feb. 2007 in $17.5 \times 12.5$-cm germination boxes (TriState Plastic, Henderson, KY) between sheets of germination paper. The germination boxes were arranged in a completely randomized design. Seeds were germinated $22{ }^{\circ} \mathrm{C}$ in natural light condition with $70 \%$ neutral light reduction. Enough water was supplied to ensure the paper was moist at all times. Seeds were considered germinated when the radicle was greater than $2 \mathrm{~mm}$ in length. Germinated seeds were planted into individual plant $11.4 \times 15.2-\mathrm{cm}$ bands (Anderson Co., Portland, OR) in Metro Mix 360 (Scotts, Marysville, $\mathrm{OH}$ ) and grown on a greenhouse bench under natural light conditions at $22.2 \pm 6{ }^{\circ} \mathrm{C}$ from 0800 to $1800 \mathrm{HR}$ and $18.3 \pm 3{ }^{\circ} \mathrm{C}$ from 1800 to $0800 \mathrm{HR}$.

On 1 June 2007, 1000 seedlings were randomly selected from 22 crosses. Unequal numbers of seedlings per cross prevented selection of equal numbers of seedlings across families. For crosses that generated fewer than 20 seedlings per family, all seedlings were used for testing. For crosses with greater than 20 seedlings per family, seedlings greater than $10 \mathrm{~cm}$ in height were used in the genetic analysis (Tables 1 and 2).

The seedlings were planted into No. 3 round plastic containers (Nursery Supplies, Chambersburg, PA) using a 9:1 mixture of finely ground, composted pine bark and Com-til®, a composted municipal biosolid (City of Columbus, Columbus, $\mathrm{OH}$ ) and placed on an outdoor container nursery. The seedlings were arranged in an incomplete randomized block design with 36 blocks (Yong-Bi Fu et al., 1998). Seedlings received pulse fertigation for two 7-min irrigation events per day from 0.03 $\mathrm{L} \cdot \mathrm{s}^{-1}$ microirrigation emitters (Roberts Irrigation Products, San Marcos, CA). Nutrients were supplied using 21N-3.1P-5.8K water-soluble fertilizer with micronutrients (J.R. Peters). Plants were fertigated twice daily from 1 June until 21 Aug. 2007 with $99.9 \mathrm{mg} \cdot \mathrm{L}^{-1}$ nitrogen. After August, the plants were pulseirrigated at the same rate described but without fertilizer. The trees were spaced at $45 \mathrm{~cm}$ on center and were treated with granular flumioxazin (Broadstar ${ }^{\mathrm{TM}}$; Valent Professional Products, Walnut Creek, CA) herbicide at $0.14 \mathrm{~g} / \mathrm{a}$.i. per container. Tree main axes were staked to bamboo canes when $45 \mathrm{~cm}$ tall. No pruning was performed, and no pesticides were applied. Trees were overwintered in a polyhouse structure with a $70 \%$ opaque white polyethylene covering with no supplemental heat. In 2008, the plants were removed from the polyhouse in May and placed on a gravel pad in full sunlight and maintained as in 2007. Guard rows were installed around the perimeter of the study each year.

Measurement of PHenotypic TRAITS AND data COLlection. Height measurements were conducted monthly from July to Sept. in 2007 and 2008. Mean branch length and number of branches were calculated in Sept. 2007 and 2008. True branches originated at $15 \mathrm{~cm}$ on the main branch and collar sprouts originated below $15 \mathrm{~cm}$ (Del Tredici, 2001). Collar sprout counts were performed during Sept. 2008. Stem diameter at $15 \mathrm{~cm}$ above pot height was measured in Sept. 2008. Branch angle was measured using a retractable protractor. Flower count was performed weekly for the early and late flowering period. Flowers last 2 to $4 \mathrm{~d}$ and are held by a persistent pedicel, called a brachyblast (Figlar, 2000; Thien, 1974). The brachyblast remains connected to the stem whether fertilization occurs. If abscised, a distinct scar remains and it can provide a method of counting flowers. 
Table 1. Height mean values on a monthly basis for Magnolia virginiana $\mathrm{F}_{1}$ half-sib family analysis in years 2007 and $2008 .{ }^{\mathrm{z}}$

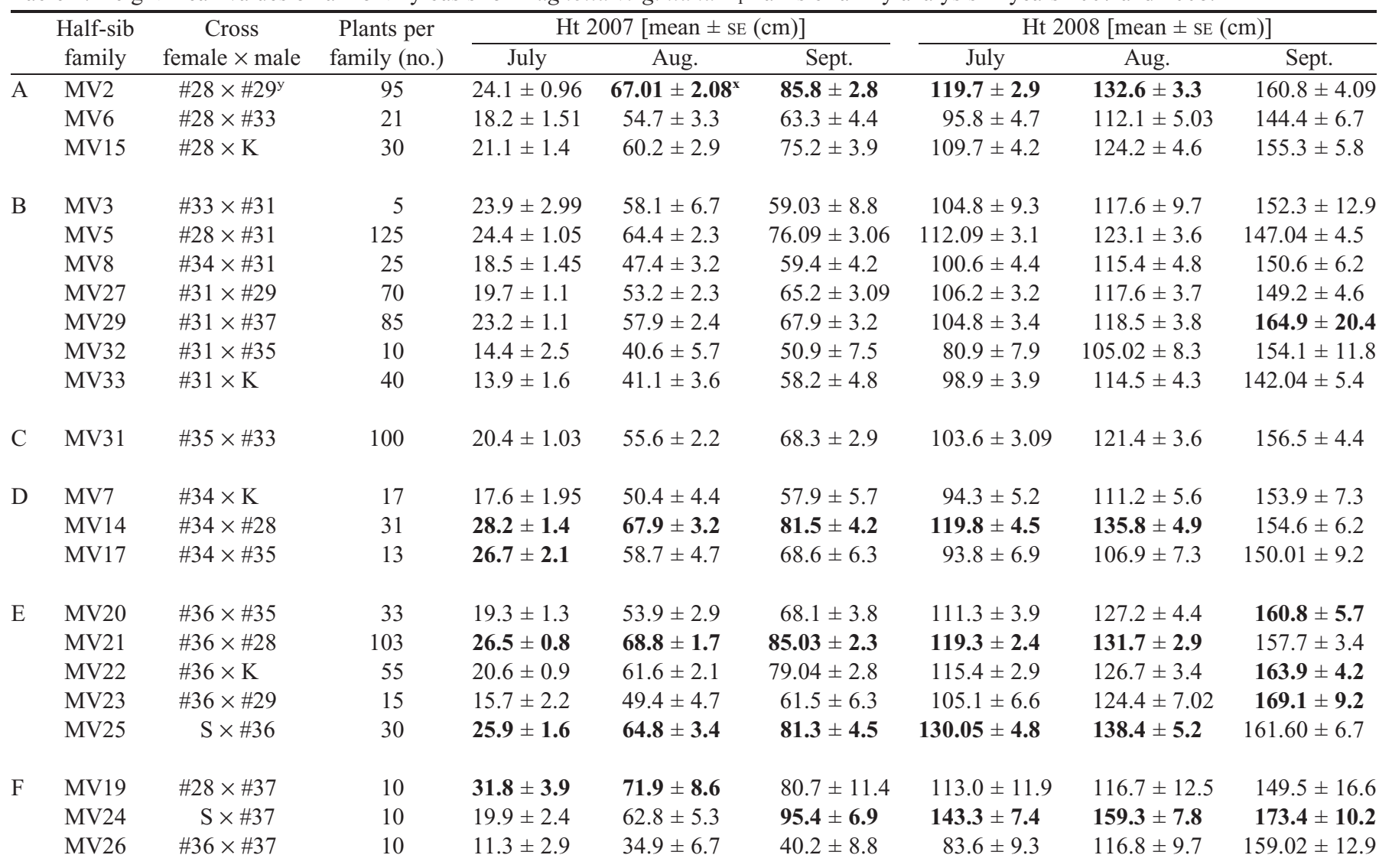

$\overline{\mathrm{z}}$ (A) Half-sib families arising from controlled pollinations with tree \#28. (B) Half-sib families arising from controlled pollinations with tree \#31. (C) Half-sib families arising from controlled pollinations with tree \#33. (D) Half-sib families arising from controlled pollinations with tree \#34. (E) Half-sib families arising from controlled pollinations with tree \#36. (F) Half-sib families arising from controlled pollinations with tree \#37. y Parent trees used to generate half-sib families are labeled as \#28, \#29, \#31, \#33, \#35, \#36, \#37, K, and S.

${ }^{x}$ Values highlighted in bold repesent five highest ranked families for given trait.

Statistical analysis. Data were subjected to analysis with the UNIVARIATE procedure (SAS Version 9.1 for Windows; SAS Institute, Cary, NC) to test for non-linearity of data and normal distribution of data before further analysis. Analysis of variance was performed using the MIXED procedure of SAS to test for family differences at the $\alpha=0.05$ level of significance. The linear model for the 2-year nursery trials is presented in Eq. [1]:

$$
\mathrm{Y}_{\mathrm{ijn}}=\mu+\alpha_{\mathrm{i}}+\beta_{\mathrm{j}}+\alpha \beta_{\mathrm{ij}}+\omega_{\mathrm{ijn}}^{\prime}
$$

where $Y_{\mathrm{ijn}}$ is the observation of $\mathrm{n}$-th tree of the $\mathrm{j}$-th family in the $i$-th block, $\mu$ is the general mean, $\alpha_{i}$ is the random effect resulting from the $\mathrm{i}$-th block, $\left(0, \sigma^{2}{ }_{\alpha}\right), \beta_{\mathrm{j}}$ is the random effect resulting from the $\mathrm{j}$-th family, $\left(0, \sigma^{2}\right), \alpha \beta_{\mathrm{ij}}$ is the random effect resulting from block $\times$ family interaction, $\left(0, \sigma_{\alpha \beta}^{2}\right)$, and $\omega_{\mathrm{ijn}}$ the random within-family effect, an error associated with an observation on an $n$-th tree in the $\mathrm{j}$-th family planted in the $\mathrm{i}$-th block, $\left(0, \sigma^{2}{ }_{\omega}\right)$.

Individual-tree, within-family, narrow sense heritability was calculated according to Cotterill (1987). Narrow sense heritabilities $\left(\mathrm{h}^{2} \mathrm{i}\right)$ were calculated in 2007 and 2008 for number of branches, mean branch length, and height. Individual-tree, within-family heritabilities were also calculated for flowering, collar sprout formation, branch angle, and caliper in 2008.
Controlled pollinations were originally performed in a diallel design, suggesting the use of full-sib analysis (Cockerham, 1963). Not all pollinations were successful and resulted in six groups of progeny, each group with a different female parent in common and differing combinations of male parents, representing a departure from the diallel mating design (Tables 1 and 2). As a result of missing data from failed controlled pollinations, analysis was performed considering progeny as half-sib families (Wright, 1976). Narrow sense heritability of traits for the half-sib family 2-year nursery trial was estimated using Eq. [2]:

$$
h_{i}^{2}=4 \sigma_{\alpha}^{2} /\left(\sigma_{\alpha}^{2}+\sigma_{\beta}^{2}+\sigma_{\alpha \beta}^{2}+\sigma_{\omega^{\prime}}^{2}\right)
$$

where $\sigma^{2}{ }_{\alpha}$ is the family variance component, $\sigma_{\beta}^{2}$ is the variance component resulting from block effect, $\sigma_{\alpha \beta}^{2}$ is the variance component resulting from family $\times$ block interaction, and $\sigma^{2}{ }_{\omega}$ is the variance resulting from random error. Variance components of random effects were estimated using the restricted maximum likelihood method of the MIXED procedure (Table 3), which is appropriate for unbalanced data (Searle et al., 1992). Leastsquare family means were calculated for all families. Leastsquare means were converted to ordinal ranks and subjected to Spearman rank correlation analysis to test for significance of rank changes between families. SES of narrow sense heritabilities were estimated using the MIXED procedure. 


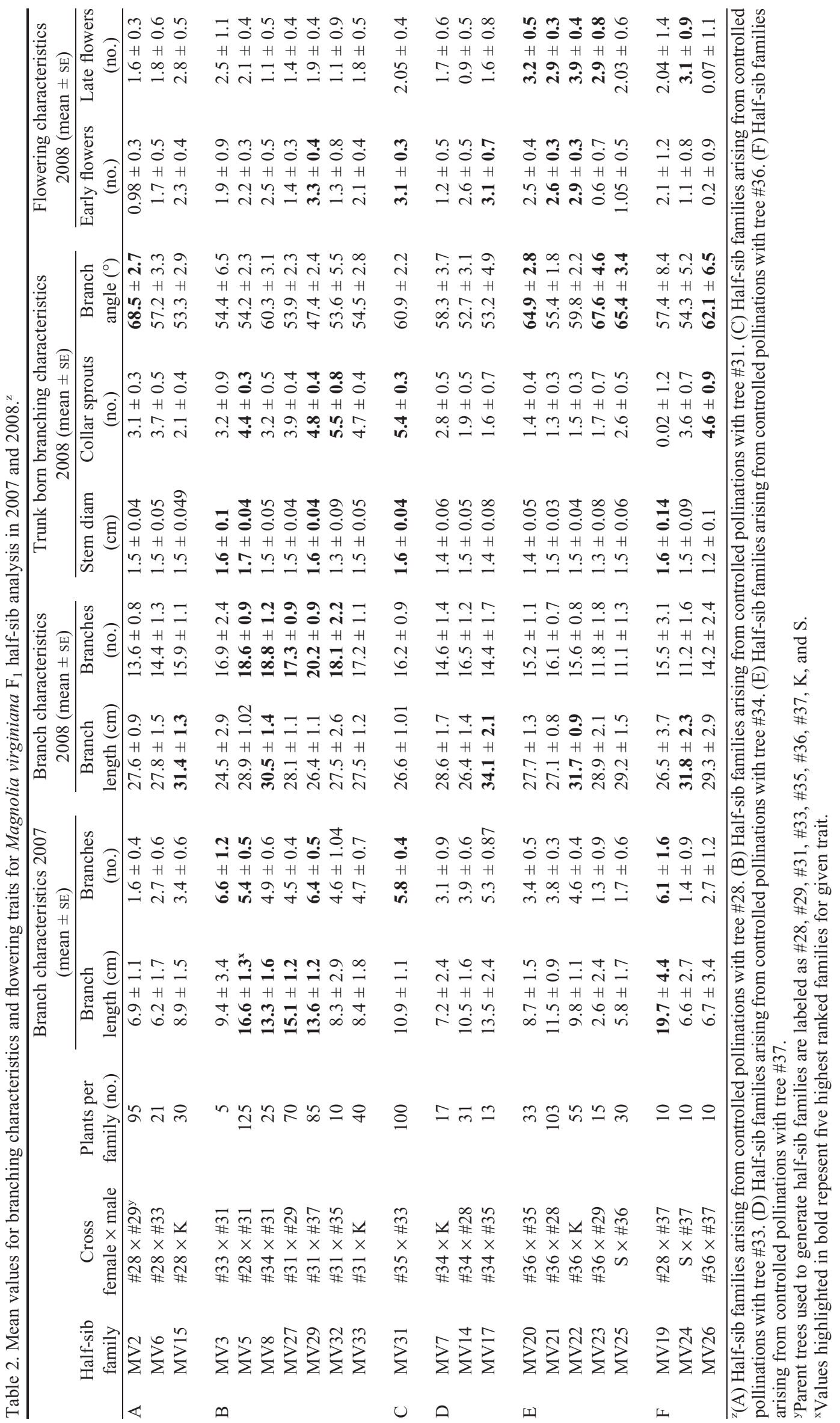




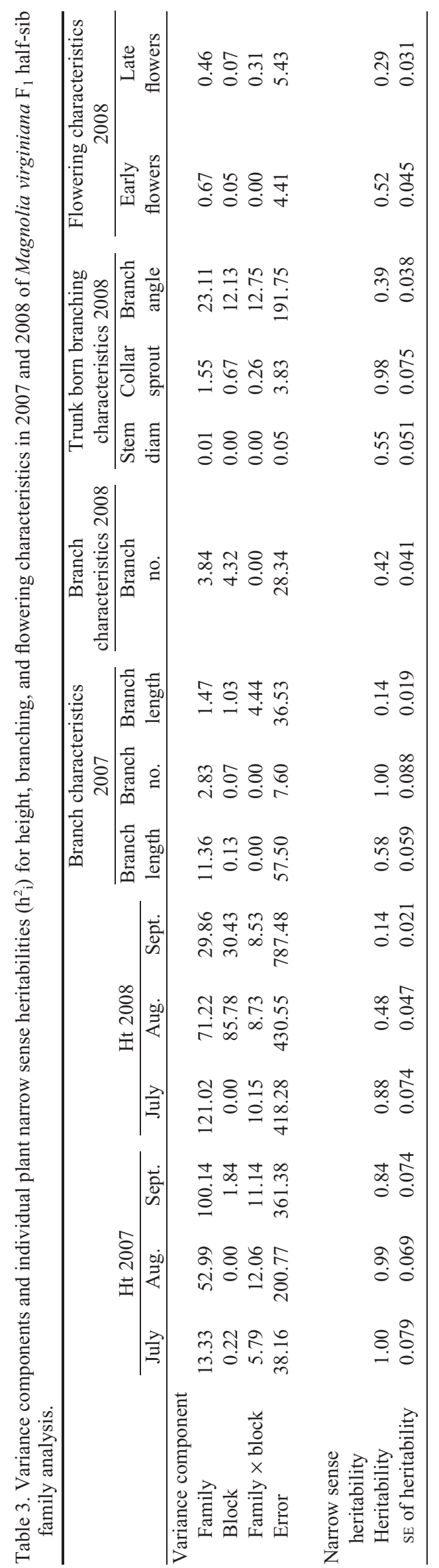

Genetic correlations were estimated for all pairwise comparisons of flowering and plant habit traits, flowering traits and height data, and form and height traits for all possible combinations of individual trees in each half-sib family using Eq. [3]:

$$
\mathrm{r}_{\mathrm{G}}=\operatorname{Cov}_{\mathrm{p}(\mathrm{x}, \mathrm{y})} /\left(\sigma_{\mathrm{p}(\mathrm{x})}^{2}+\sigma_{\mathrm{p}(\mathrm{y})}^{2}\right)^{0.5}
$$

where $\operatorname{Cov}_{p(x, y)}$ is the family within set component of covariance between traits $\mathrm{x}$ and $\mathrm{y}$ and $\sigma_{\mathrm{p}(\mathrm{x})}^{2}$ and $\sigma_{\mathrm{p}(\mathrm{y})}^{2}$ are the corresponding family covariances for those traits. Family variances were estimated using the covariance test option of the MIXED procedure on the sum of traits $\mathrm{x}$ and $\mathrm{y}$ using Eq. [4] (Vargas-Hernandez et al., 2003):

$$
\operatorname{Cov}_{\mathrm{p}(\mathrm{x}, \mathrm{y})}=\left(\sigma_{\mathrm{p}(\mathrm{x}+\mathrm{y})}^{2}-\sigma_{\mathrm{p}(\mathrm{x})}^{2}-\sigma_{\mathrm{p}(\mathrm{y})}^{2}\right) / 2
$$

Family mean phenotypic correlations were calculated for all pairwise comparisons of flowering and form traits, flowering traits and height data, and form and height traits. Correlations were performed for all traits in both years where possible. Least-square family means were calculated for the test resulting from unequal numbers of progeny in each half-sib family. Correlations were analyzed using the CORR procedure of SAS.

\section{Results}

Differences were found among half-sib families $(P \leq 0.05)$ for all height and branching measurements, stem diameter, collar sprout formation, and branch angle (Table 4). There were also significant differences $(P \leq 0.0001)$ between families for both early and late flower production. Block effect was significant for Aug. and Sept. 2008 height measurements as well as mean branch length, branch number, stem diameter, branch angle, and collar sprouts in 2008 , indicating a possible genotype $\times$ environment interaction for these traits.

There were rank changes between families for height, mean branch length, and number of branches between 2007 and 2008. Rank changes in height between end-of-year measurements in Sept. 2007 and Sept. 2008 were significant (Spearman's $r=$ $0.37, P \leq 0.05$ ). Rank changes between mean branch length and branch count in 2007 and 2008 were also significant (Spearman's $r=0.61, P \leq 0.0001)$.

Growth (as measured by height increase) was rapid; the amount of change ranged from 40 to $95 \mathrm{~cm}$ per year in 2007 and 142 to $173 \mathrm{~cm}$ per year in 2008 (Table 1). There were rank changes for height among families from 2007 to 2008, but family MV24 ranked the highest in both 2007 and 2008. There were rank changes for branch number and mean branch length from 2007 to 2008. In 2007, MV5 and MV19 were ranked among the five highest families for both mean branch length and branch count, respectively (Table 2). During 2008, MV5 ranked in the top five for number of branches but not mean branch length. MV19 did not rank in the top five for either trait in 2008. Two of the highest ranked families for mean branch length in 2008, MV22 and MV24, were also ranked in the five highest families for late flower production. MV29 was in the top ranked families for branch count in 2007 and 2008 and ranked highly for caliper, collar sprout, and early flower production. MV29 was ranked in the top five families more than any other family.

For the early flowering period, family MV29 was the highest ranked family with a mean value of 3.3 flowers per plant, 


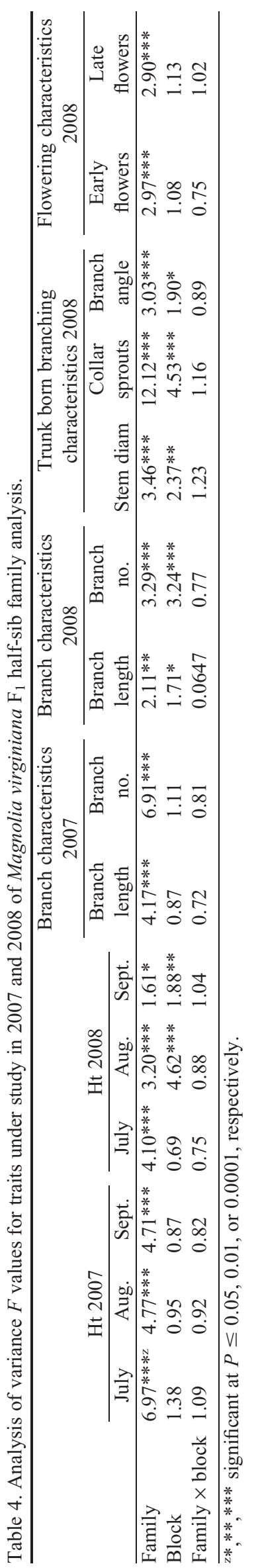

whereas family MV32 was the lowest ranked, producing only 0.22 flowers per plant (Table 2). Only two of the five highest ranked families for early flower production were ranked among the highest five for late flower production. For late flowering, the number of flowers ranged from a low of 0.07 in MV26 to a high of 3.9 in MV22. Four of the highest ranked families for late flower production had tree \#36 as the maternal parent, and one other family with this parent ranked in the highest five families for mean branch length, whereas four families for branch angle and three families for height had tree \#36 as a parent.

There were significant, positive family mean phenotypic correlations. Family height means were positively phenotypically correlated $(P \leq 0.05)$ with late flower production at all measurement times except July 2007 height (Table 5). Mean branch length and branch number displayed inverse relationships with respect to early and late flower production, which suggested differing genetic bases for these traits. Branch count was significantly $(P \leq 0.0001)$ correlated with early flower production in $2007(r=0.80)$ and $2008(r=0.68)$ (Table 5). Mean branch length was also correlated with early flower production in $2007(r=0.67, P \leq 0.0001)$ but was not significant in $2008(r=0.17)$. There was a correlation between stem diameter and early flower production $(r=0.70, P \leq$ $0.0001)$ in 2008. Branch number and stem diameter were phenotypically correlated with each other in $2007(r=0.63$, $P \leq 0.01)$ and $2008(r=0.63, P \leq 0.01)$.

Estimated genetic correlations were similar to corresponding phenotypic family mean correlations. All height measurements in 2007 and 2008 were moderately to strongly positively genetically correlated at all stages of development $(r=0.30$ to 1.00 ) but showed a moderate to strong negative correlation with mean branch length, branch number, and collar sprout count in 2007 and 2008 (Table 6). Height in 2007 was negatively correlated with branch angle, but height and branch angle in 2008 were positively correlated, and the strength of that correlation increased through the September measurements (Table 6). Early flowering period was strongly positively correlated with branch count $(r=0.72)$ and mean branch length $(r=0.83)$ in 2007 , but moderately negatively correlated with branch count $(r=-0.16)$ and mean branch length $(r=-0.25)$ in 2008 (Table 6), which differed from phenotypic correlation in which the relationship was positive in 2007 and 2008. Late flowering production was negatively correlated in 2007 and 2008 with mean branch length $(r=-0.43$ and $r=-0.04$, respectively) and branch count $(r=-0.35$ and $r=-0.45$, respectively) and strongly positively correlated with height growth from Aug. $2007(r=0.95)$ through Sept. $2008(r=1.00)$ (Table 6). Late flower production was positively phenotypically correlated with mean branch length $(r=0.34)$ in 2008, but genetically uncorrelated $(r=-0.03)$ in 2007 (Table 6).

Collar sprout bud formation appeared during the first year of container production, but shoot development was delayed until 2008. Collar sprout formation was positively correlated only with mean branch length and number of branches in 2007, but in 2008, collar sprout formation was correlated with branch count. Collar sprout formation was moderately negatively correlated with all height data in 2007 and 2008 (Table 6).

Narrow sense heritabilities were calculated on an individual plant basis and varied greatly for the traits measured in 2008 (Table 3). Individual plant narrow sense heritabilities for firstyear seedling traits were high for all traits measured except for mean length of branches, which displayed moderate heritability 


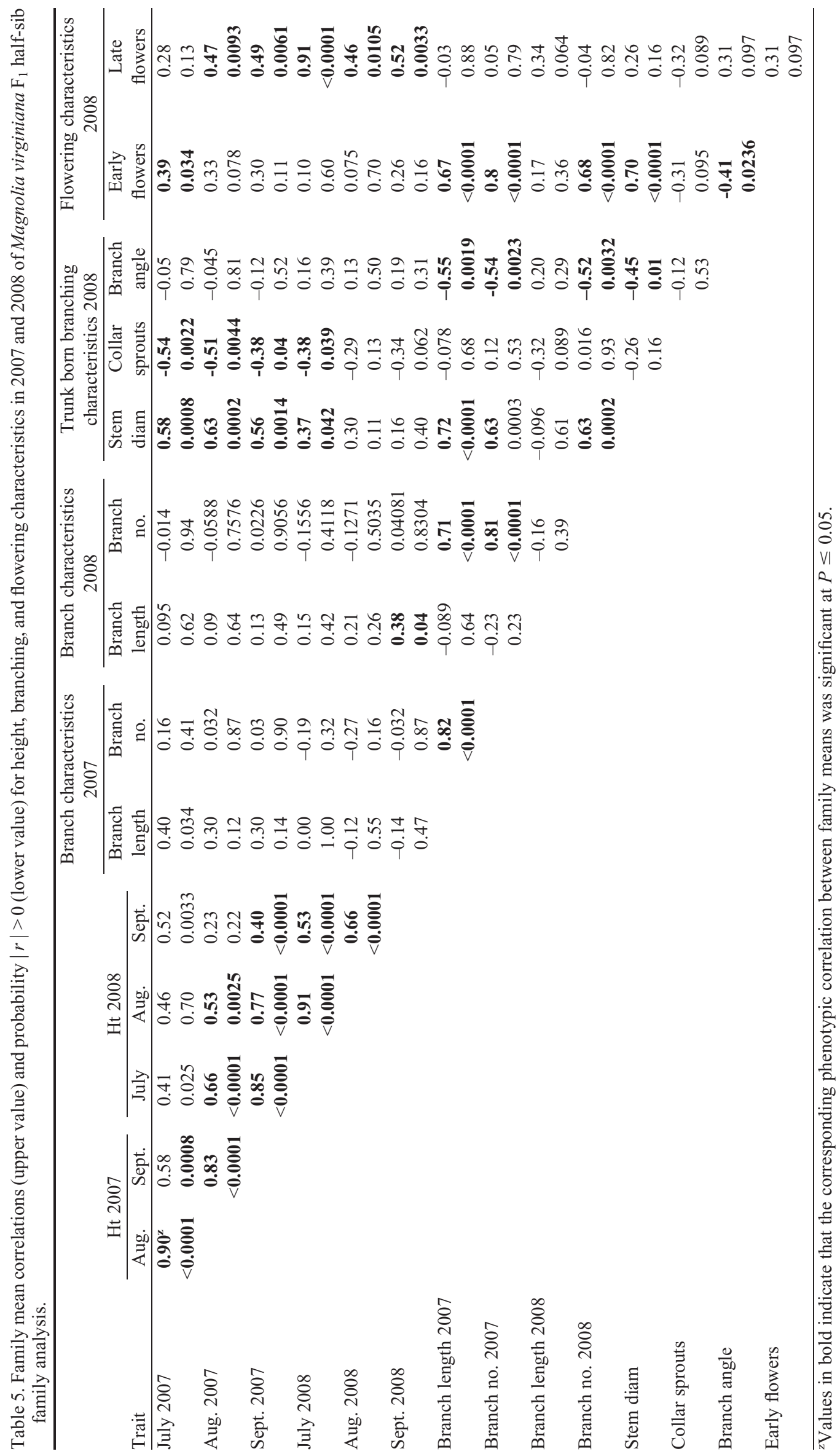




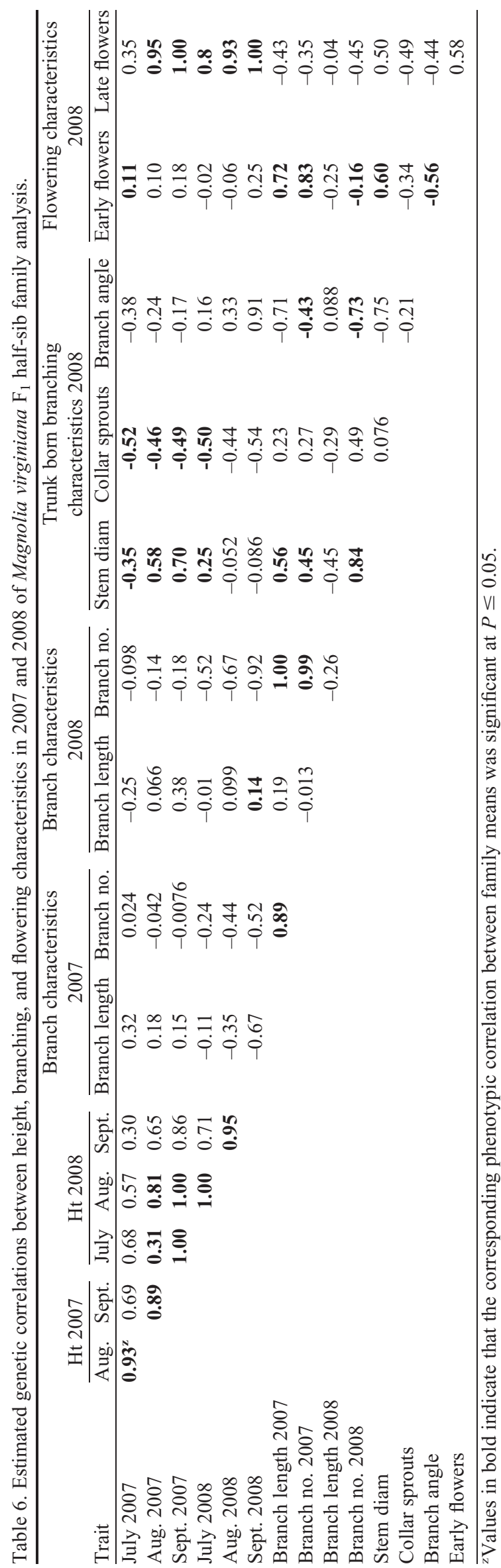

as found in other taxa (Zobel and Talbert, 1984). Heritability for height was high in 2007 , ranging from 0.84 to 1.00 , but lower in 2008 ranging from 0.88 in July to 0.14 in September (Table 3). Heritabilities for branch number (1.00) and mean branch length $(0.58)$ were also high during 2007. Second-year measurements were lower for branch count and mean branch length, 0.42 and 0.14 , respectively. Family means and block effects were significant for these traits, and the moderate to low heritabilities for these traits suggest that height growth has a large environmental component.

Collar sprout formation, caliper, and branch angle were all under moderate to strong genetic control in 2008 (0.98, 0.55, and 0.39 , respectively; Table 3 ). The narrow sense heritability estimates for early and late flower production were 0.52 , and 0.29 , respectively.

\section{Discussion}

The goal of this study was to provide the knowledge needed to develop an efficient selection method for two ideotypes that might be achieved through selection of a diverse $M$. virginiana breeding population. The following conclusions may be drawn from this 2-year study: 1) number of branches, stem diameter, and early flower production are positively phenotypically and genetically correlated and could form the basis of a selection index for compact, shrub-form ideotypes; 2) height is phenotypically and genetically correlated with late flower production and negatively phenotypically and genetically correlated with collar sprout formation and could form the basis of a selection index for the single-stemmed, small tree ideotype.

The data suggested formulation of two selection indices for plants in our population that reflect our breeding goals. The high and positive phenotypic and genetic correlations between number of branches and early flower production suggested the formation of the first selection index for compact, shrub-habit ideotype. The phenological link between flowers and branching is as follows: flowers are borne terminally in M. virginiana on a modified branch, the brachyblast (Figlar, 2000). During flower senescence, lateral branches develop when released from dormancy, and typically one branch becomes dominant, forming a new terminal shoot axis (Fig. 1). There is variation for the number of new lateral branches initiated at flower senescence (Table 3). Plants that produced higher numbers of branches have the highest potential for increased early flower production. Strong positive phenotypic correlations between number of branches and early flower production in 2008 would allow for selection of short individuals with increased numbers of branches. Strong negative genetic correlation between number of branches and height in September is consistent with the development of the shrub habit ideotype. Families MV29 and MV31 ranked among the highest five families for flower production and were also ranked among the five families for highest number of branches in 2007. Furthermore, because of determinate flowering in M. virginiana, it follows that the number of branch tips determines the potential number of flowers. The moderate heritability for early flower production $(0.53)$ and for number of branches $(0.42)$ as well as low heritability for height in 2008 suggested that selection for short individuals that are heavily branched will result in concomitant selection for larger numbers of early flowers.

Formation of a selection index for increased numbers of flowers and branches has been suggested for Magnolia grandiflora 


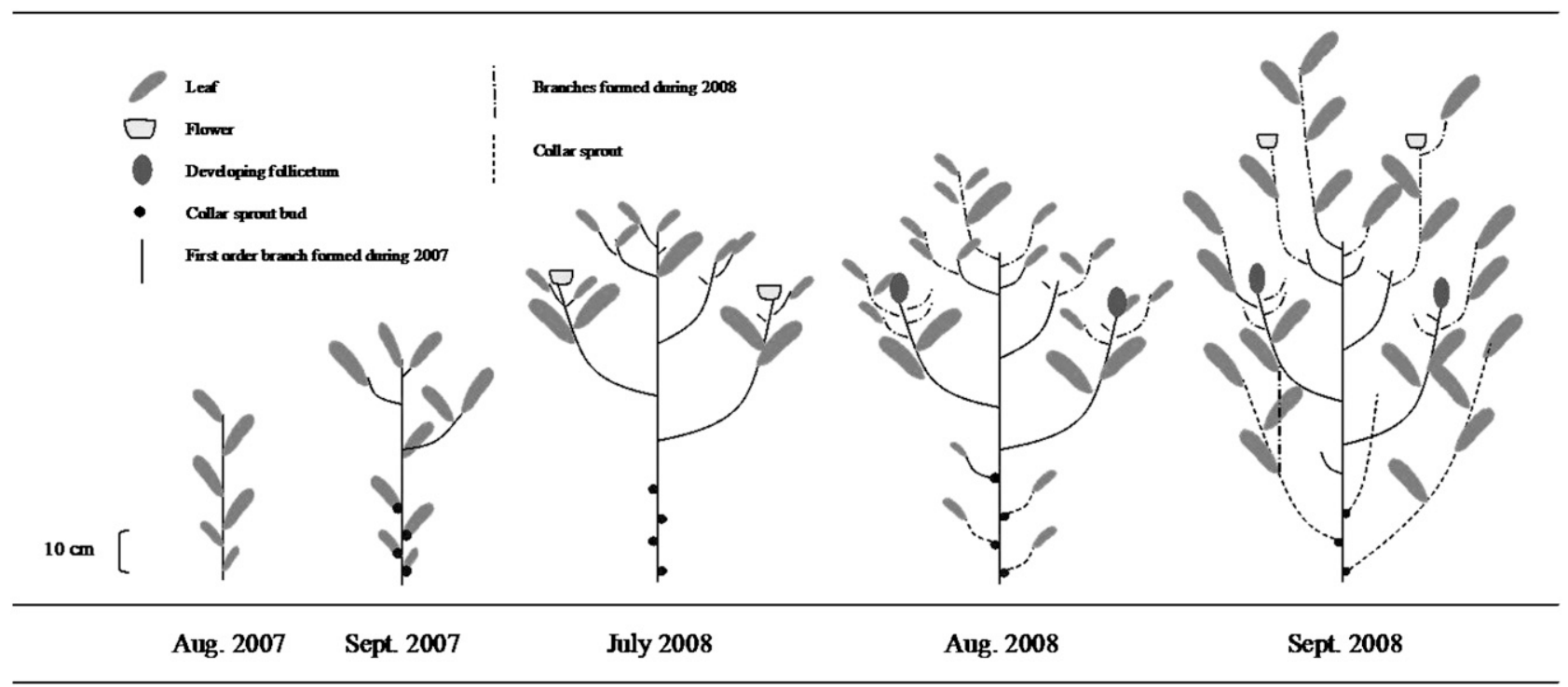

Fig. 1. Stylized plants of Magnolia virginiana are drawn to scale and based on the mean growth response reported in Tables 1 and 2.

(Greene, 1991). In a progeny trial in eastern Texas, a weak but positive relationship was found between stem diameter and flower production, but these traits were inversely related to height in the third year of the field nursery trial. It was hypothesized that selection for more profuse flowering would indirectly select for compact plants with increased branching. A supporting relationship has been suggested for $M$. grandiflora 'Little Gem' in which increased numbers of branches resulted in increased flower production and a reduced growth rate. It has been proposed by an experienced large-scale magnolia producer that production of a single flower reduces the height and branch growth of $M$. grandiflora 'Little Gem' by $10 \mathrm{~cm}$ (R. Head, personal communication), supporting the interpretation of the effect of flower abundance on plant size. In our study, height and early flower production were negatively correlated. Abundant reproductive growth would divert plant assimilates from vegetative growth, thus reinforcing a compact form (Gifford and Evans, 1981; Herms and Mattson, 1991; Luken, 1987).

Concomitant selection for number of branches and early flower production also selects for increased collar sprout formation. In this study, the only evidence of collar sprouts was the development of axillary buds in 2007 that did not elongate and may have required a cold period to activate growth (Cline and Harrington, 2007). In 2008, these buds elongated, but their growth did not occur among all members of a half-sib family. Formation of collar sprouts was highly heritable and there was a weak relationship between collar sprout formation and number of branches in both 2007 and 2008. This may add increased branching density to the shrub-form ideotype. It was originally hypothesized that collar sprout formation was under predominantly environmental control and induced by environmental stress such as soil moisture. The uniform nursery production system and high narrow sense heritability $(0.98)$ suggested that collar sprout formation may represent an important developmental phase in $M$. virginiana and may signal changes in apical dominance and apical control mechanisms as a result of a switch from the juvenile to the mature phase (Franklin, 1979). Study of mature plants shows that collar sprout formation may be directly responsible for the phenotypes of $M$. virginiana seen in landscapes and that selection indices cannot be imposed on young plants because collar sprout formation occurs only in older plants.

For shrub-form ideotypes, the highest ranking individuals from the highest ranking families should be selected for further evaluation and use in controlled pollinations. Further testing is required to determine the degree of rank change among families for these traits. It is possible that changes in rank from 2007 to 2008 represent a genotype $\times$ environment interaction that would limit the effectiveness of early selection (Rweyongeza et al., 2003).

Tall plants with few branches and increased late flower production describe the second ideotype. The strong positive phenotypic and genetic correlations between late flower production and height in 2007 and 2008 suggested that selection for late flowering types would also select taller plants. There was a negative correlation between collar sprout formation and late flower production that suggested selection for tall plants would also select late flowering forms with reduced collar sprout formation and a greater likelihood of retaining a single main axis.

Late flower production may be difficult to exploit in families in which the emphasis is on increased early flower production and heavy branching. The strong genetic correlation between height and late flower production and environmental influence suggested by significant block effect implies that increased late flowering is dependent on plant growth rate or continued elongation of terminal axes. This suggests the necessity of fertilizer and water inputs and the initiation of a second growth phase for maximum late flower production to be evident (Fig. 1). Rapid elongation of terminal shoots during summer is referred to as lammas growth (Cline and Harrington, 2007). Flowers were produced terminally on lammas growth of the terminal axes. Proximal branching during this phase was under strong apical dominance, but collar sprouts appeared to be independent and exhibited free growth. Terminal axes of $M$. virginiana exhibited determinate growth and were characterized by the formation of flowers concomitant with the initiation of a lateral bud. The lateral bud acted as a reiterate for the terminal axis and continued to grow vertically and exhibited apical dominance. 
Selection for late flowering may be further complicated by the low heritabilities for growth traits and moderate heritability for late flowering. Low heritabilities for these traits suggested that optimal nursery conditions were the major factors in producing late-season flowers. Genetic relationships for all traits in this species may be clarified by a survey of germplasm encompassing the entire range of distribution of this species, because there may be more genetic variation available in other populations of $M$. virginiana var. virginiana or $M$. virginana var. australis (Wright, 1976; Zobel and Talbert, 1984).

Our study suggested useful parameters for development of a targeted, rapid selection program; however, the sharp decrease in narrow sense heritability for height and branching data between 2007 and 2008 demonstrates that longer periods are needed to adequately evaluate seedlings to determine genetic control of traits and develop more well-defined selection indices. Alternatively, the decrease in heritability may also be associated with the transition from the juvenile to mature growth phase. Hastening the onset of the mature genotypic phase by inducing fast growth at close spacing, similar to that done in this study, could improve the prediction of family ranking at a mature age (Franklin, 1979).

Another issue concerns the proper interpretation of genetic tests for this population of $M$. virginiana. Unlike wind-pollinated, outcrossing species typically used in forestry studies, magnolia species are reported to be self-pollinating (Ishida et al., 2003; Wright, 1976). Past inbreeding events in this population could have led to overestimation of covariance between relatives and be further confounded by non-independence of experimental errors (Dudley and Moll, 1969). Also, if past inbreeding did occur, the result would be altered probabilities that alleles are identical by descent because assumptions of independence are violated (Namkoong, 1979). The overestimation of genetic correlations and high heritabilites suggest possible inbreeding. Another constraint was the unequal replication of families and associated low numbers of individuals in some families.

This study represents a starting point in a long-term improvement program for $M$. virginiana. Additional genetic testing of a wider range of $M$. virginiana genotypes is necessary to validate the results of this study. The decrease in heritability and significant block effect suggests environmental factors likely influence height and branching traits, necessitating additional nursery and field testing with accessions from a wider geographical range.

\section{Literature Cited}

Azuma, H., R.B. Figlar, P. Del Tredici, K. Camelbeke, A. PalmerolaBejerano, and M.S. Romanov. 2011. Intraspecific sequence variation of cpDNA shows two distinct groups within Magnolia virginiana L. of eastern North America and Cuba. Castanea (in press).

Blake, M.K. and D. Struve. 2007. Update on sweetbay magnolia breeding at the Ohio State University. J. Magnolia Soc. 42:15-21.

Callaway, D.J. 1994. The world of magnolias. Timber Press, Portland, OR.

Cline, M.G. and C.A. Harrington. 2007. Apical dominance and apical control in multiple flushing of temperate woody species. Can. J. For. Res. 37:74-83.

Cockerham, C.C. 1963. Estimation of genetic variances, p. 53-93. In: Hanson, W.D. and H.F. Robinson (eds.). Statistical genetics and plant breeding. Natl. Acad. Sci. Natural Resource Council, Washington, DC. Cotterill, P.P. 1987. Short note: On estimating heritability according to practical applications. Silvae Genet. 36:46-48.

Del Tredici, P. 1981. Magnolia virginiana in Massachusetts. Arnoldia 39:36-49.
Del Tredici, P. 2001. Sprouting in temperate trees: A morphological and ecological review. Bot. Rev. 67:121-140.

Dirr, M.A. 1998. Manual of woody landscape plants: Their identification, ornamental characteristics, culture, propagation, and uses. Stipes, Champaign, IL.

Dudley, J.W. and R.H. Moll. 1969. Interpretation and use of estimates of heritability and genetic variances in plant breeding. Crop Sci. 9:257-262.

Figlar, R.B. 2000. Proleptic branch initiation in Michelia and Magnolia subgenus Yulania provides basis for combinations in subfamily Magnolia. Proc. Intl. Symp. Family Magnoliaceae 2:14-25.

Franklin, E.C. 1979. Model relating levels of genetic variance to stand development of four North American conifers. Silvae Genet. 28:207-212.

Gardiner, J. 2000. Magnolias: A gardener's guide. Timber Press, Portland, OR.

Gifford, R.M. and L.T. Evans. 1981. Photosynthesis, carbon partitioning, and yield. Annu. Rev. Plant Physiol. 32:485-509.

Greene, T.A. 1991. Family differences in growth and flowering in young southern magnolia. HortScience 26:302-304.

Herms, D.A. and W.A. Mattson. 1991. Does reproduction compromise defense in woody plants? p. 35-46. In: Baranchikov, Y.N., W.J. Matison, F.P. Hain, and T.L. Payne (eds.). Forest insect guilds: Patterns of interaction with host trees. U.S. Dept. Agr. For. Serv. Gen. Tech. Rpt. NE-153.

Ishida, K., H. Yoshimaru, and I. Hiroki. 2003. Effects of geitenogamy on seed set of Magnolia obovata Thunb. (Magnoliaceae). Intl. J. Plant Sci. 164:729-735.

Jonsson, L. 1987. How easy is pollen collecting? J. Magnolia Soc. 22:1-3. Luken, J.O. 1987. Interactions between reproduction and vegetative growth in staghorn sumac Rhus typhina L. Bull. Torrey Bot. Club 114:247-251.

MacDonald, B. 1986. Practical woody plant propagation for nursery growers. Timber Press, Portland, OR.

McDaniel, J.C. 1966. Variations in the sweet bay magnolia. Bul. Morris Arboretum 17:7-12.

McDaniel, J.C. 1970. Two cultivars for upgrading Magnolia virginiana seedling production. Proc. Intl. Plant Prop. Soc. p.199-207.

McDaniel, J.C. 1984. What can we do with sweet bay magnolia? J. Magnolia Soc. 19:24-29.

Namkoong, G. 1979. Introduction to quantitative genetics in forestry. U.S. Dept. Agr. For. Serv. Tech. Bul. 1588.

Nash, L.J. and W.R. Graves. 1993. Drought and flood stress effects on plant development and leaf water relations of five taxa of trees native to bottomland habitats. HortScience 118:845-850.

Priester, D.S. 1990. Magnolia virginiana L. sweetbay, p. 449-454. In: Burns, R.M. and B.H. Honkala (eds.). Silvics of North America. Vol. 2: Hardwoods. U.S. Dept. Agr. For. Serv. Agr. Hdbk. 654.

Rweyongeza, D.M., F.C. Yeh, B.P. Dancik, and N.K. Dhir. 2003. Genetic variation in height, branch, and needle lengths of Pinus sylvestris L. from Siberia tested in Alberta, Canada. Silvae Genet. 52:52-60.

Searle, S.R., G. Casella, and C.E. McCulloch. 1992. Variance components. Wiley, New York, NY.

Spongeberg, S.A. 1976. Magnoliaceae hardy in temperate North America. J. Arnold Arbor. 57:250-312.

Struve, D.K. and S. McKeand. 1993. A means of accelerating red oak genetic tests. Ann. Sci. For. 50:410s-415s.

Thien, L.B. 1974. Floral biology of Magnolia. Amer. J. Bot. 61:10371045.

Treseder, N.G. 1978. Magnolias. Faber and Faber, London, UK.

Vargas-Hernandez, J.J., W.T. Adams, and D.G. Joyce. 2003. Quantitative genetic structure of stem form and branching traits in douglas-fir seedlings and implications for early selection. Silvae Genet. 52:36-44.

Wright, J.W. 1976. Introduction to forest genetics. Academic Press, New York, NY.

Yong-Bi Fu, G., P.Y. Clarke, G. Namkoong, and A.D. Yanchuk. 1998. Incomplete block designs for genetic testing: Statistical efficiencies of estimating family means. Can. J. For. Res. 28:977-986.

Zobel, B. and B.J. Talbert. 1984. Applied forest tree improvement. Wiley, New York, NY. 